\title{
GREEN SYNTHESIS OF COPPER NANOPARTICLES USING Uncaria gambir ROXB. LEAF EXTRACT AND ITS CHARACTERIZATION
}

\author{
N. Elisma ${ }^{1}$, A. Labanni ${ }^{1}$, Emriadi $^{1}$, Y. Rilda $^{1}$, M. Asrofi ${ }^{2}$ and S. Arief ${ }^{1, *}$ \\ ${ }^{1}$ Department of Chemistry, Andalas University, Padang, West Sumatera, 25163, Indonesia \\ ${ }^{2}$ Department of Mechanical Engineering, Andalas University, Padang, \\ West Sumatera, 25163, Indonesia \\ *E-mail: syukriarief@gmail.com
}

\begin{abstract}
In this paper, the copper nanoparticle has been synthesized based on green synthesis method using Uncaria gambir Roxb. leaf extract without capping agent or external energy. It was characterized by UV-Visible Spectrophotometry, X-ray Diffraction, Fourier Transform Infra-red, and Transmission Electron Microscopy analysis. Copper nanoparticles formation was recognized by color changes to dark brown and was furtherly proven by UV-Vis spectrophotometer analysis based on the absorption band at 400 to $415 \mathrm{~nm}$. X-ray Diffraction pattern performed three sharp peaks specifically referred to face-centered cubic structured of metallic copper. Transmission Electron Microscopy analysis result confirms the spherical copper nanoparticles formation in diameter of $2.5-15 \mathrm{~nm}$.

Keywords: Green synthesis, copper nanoparticles, Uncaria gambir Roxb., bioreducing agent, chemical reduction.

(C) RASĀYAN. All rights reserved
\end{abstract}

\section{INTRODUCTION}

There is an increase in the use of copper due to its properties such as highly conductive, good potential reduction and more economic compared to silver and gold. In the last decade, nano-copper was trended and developed by many researchers because of its unique properties. The advantages of nano-copper include high contact surface area, stable properties, and its wide potential in various field i.e. catalyst, detectors, optical sensor, and antimicrobial agent. ${ }^{1}$

Several methods have been proposed to synthesize copper nanoparticles such as mechanical milling, ${ }^{2}$ electrochemical, ${ }^{3}$ vapor deposition, ${ }^{4}$ and chemical reduction. ${ }^{5}$ Among these methods, the chemical reduction is a low-cost production and the simplest method to produce copper nanoparticles. Qiu-Li ${ }^{5}$ and Karikalan ${ }^{6}$ report the use of potassium borohydride and trisodium citrate, respectively, to obtain copper nanoparticles. However, the use of pure chemical reagent is costly and is not environmentally friendly.

Recently, the use of plant extract to obtain copper and silver nanoparticle had been carried out such as tea $^{7}$, Magnolia kobus $^{8}$, starch $^{9}$ and other plants. ${ }^{10}$ Meanwhile, those studies still use chemical capping agent as a stabilizer to prevent agglomeration of copper nanoparticles. However, the using of chemical capping agent indicates that it is not friendly to the environment and adds value cost production.

Therefore, in present work natural material was used to synthesize copper nanoparticle (CuNps). Uncaria gambir Roxb. as one of the main plant in West Sumatera, Indonesia which has been long time utilized as a traditional medicine to cure diarrhea, headaches, sore skin, fever, and others. ${ }^{11}$ This is due to the content of tannin in the leaf. In our previous studies, it was employed as bioreducing agent in synthesizing silver nanoparticles. ${ }^{12-15}$ As far as we know, this is the first study reporting about the using of Uncaria gambir Roxb. leaf extract as a reducing agent to synthesize copper nanoparticles. The UV-Visible Spectrophotometry (UV-Vis), Fourier Transform Infra-Red (FTIR), X-ray Diffraction (XRD), and Transmission Electron Microscopy (TEM) analysis were carried out to characterize the product.

Rasayan J. Chem., 12(4), 1752-1756(2019)

http://dx.doi.org/10.31788/RJC.2019.1245347

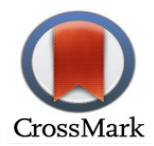


RASĀYAN J. Chem.

Vol. 12 | No. 4 |1752 - 1756| October - December | 2019

\section{EXPERIMENTAL}

Fresh Uncaria gambir Roxb. leaves were obtained from Payakumbuh, West Sumatera, Indonesia. Copper sulphate (Merck) with 99\% purity. Distilled water was supplied from the Department of Chemistry, Andalas University, Indonesia.

Uncaria gambir Roxb. leaves were washed several times and shade dried for 5 days in room temperature. The dried leaves were mechanically grounded at $500 \mathrm{rpm}$ for an hour. As many as $10 \mathrm{~g}$ leaf powders were mixed with $100 \mathrm{~mL}$ distilled water in beaker glass and then boiled at $65{ }^{\circ} \mathrm{C}$ at $1500 \mathrm{rpm}$ for 2 hours. The mixture solution was cooled in room temperature. It was then filtered by using filter paper (Whatman no. 1) to obtain a clear solution. The extract was stored in a refrigerator at a temperature of $4{ }^{\circ} \mathrm{C}$ for future use.

An amount of $0.0249 \mathrm{~g}$ of solid copper was dissolved in $100 \mathrm{~mL}$ of distilled water in beaker glass to obtain $0.001 \mathrm{M}$ copper sulphate solution. As many as $20 \mathrm{~mL}$ of leaf extract solution of Uncaria gambir Roxb. was added to $40 \mathrm{~mL}$ of $0.001 \mathrm{M}$ copper sulphate solution. The mixture was stirred at room temperature at a speed of $1000 \mathrm{rpm}$ for 24 hours. It was in colloid suspension and stored in the chamber. After that, the colloid was dried in a drying oven at $50{ }^{\circ} \mathrm{C}$ for 2 hours to get CuNP powders.

The CuNPs was analyzed by UV-Vis spectrophotometer Specord 200 in a wavelength range of 300-700 $\mathrm{nm}$. FTIR Shimadzu was used to determine the functional group of all tested samples in wavelength of $400-4000 \mathrm{~cm}^{-1}$ under the resolution of $4 \mathrm{~cm}^{-1}$. The crystal structure of powder samples was determined by XRD X'PERT Powder Panalytical instrument with the voltage and current applied during testing were 40 $\mathrm{kV}$ and $35 \mathrm{~mA}$, respectively. The diffraction was scanned from $20-80^{\circ}$. The morphology and distribution size of CuNPs were observed by TEM JEM-JEOL 1400 instrument with a voltage level of $100 \mathrm{kV}$.

\section{RESULTS AND DISCUSSION}

The stability of copper nanoparticles was analyzed using UV-Vis spectrophotometer based on time function (Fig.-1). Peak a and b show the absorption peak of Uncaria gambir Roxb. extract and CuSO4 in wavelength of $270 \mathrm{~nm}$ and $250 \mathrm{~nm}$, respectively. After the reaction, the peaks were shifted and a new peak was formed at a wavelength of $400-410 \mathrm{~nm}$, refers to CuNPs formation. ${ }^{16}$ The formation of CuNPs absorption peaks was caused by the presence of plasmon ribbons on the colloidal surface of $\mathrm{Cu}$, which clearly suggested that reduction process of $\mathrm{Cu}^{2+}$ to $\mathrm{Cu}^{0}$ was successfully occurred by the content of leaf extract ${ }^{17}$. A similar study was reported by Salavati-Niasari et al ${ }^{18}$ about CuNPs synthesized by chemical reduction methods which showed an absorption peak at $411 \mathrm{~nm}$. However, there was a significant increase in absorbance from 7 to 21 days for 0.82 to 1.65 , respectively. After 21 days, there was a decrease in absorbance. This result indicated the beginning of larger clusters formation due to the aggregation of CuNPs.

FT-IR spectroscopy analysis was performed to determine the functional groups in Uncaria gambir Roxb. leaf extract and CuNPs before and after the reduction process. In Figure-2 (a) a typical absorption peak of Uncaria gambir Roxb. leaf extract with a wider and strong band was observed at $3342 \mathrm{~cm}-1$ due to the presence of an $\mathrm{OH}$ bond of the phenolic group. The $\mathrm{O}-\mathrm{H}$ strain of the hydroxyl group is marked at the peak of $3850 \mathrm{~cm}-1$. The peaks of $1898 \mathrm{~cm}-1$ and $1635 \mathrm{~cm}-1$ show the presence of cluster $\mathrm{C}=\mathrm{O}$ and the existence of the $\mathrm{H}-\mathrm{O}-\mathrm{H}$ bond, respectively. ${ }^{19}$

Meanwhile, the IR spectrum of the CuNPs showed absorption at $3289 \mathrm{~cm}^{-1}, 2181 \mathrm{~cm}^{-1}, 1601 \mathrm{~cm}^{-1}, 1373$ $\mathrm{cm}^{-1}$, and $748 \mathrm{~cm}^{-1}$ for $-\mathrm{OH}, \mathrm{CH}$ aliphatic, $\mathrm{C}=\mathrm{O}$ groups, $\mathrm{CO}$ groups and $\mathrm{C}=\mathrm{C}$, respectively. ${ }^{20}$ The shift of the wavenumber that clearly observed between Uncaria gambir Roxb and CuNPs indicates there is an interaction functional group between Uncaria gambir Roxb and CuNPs. The $\mathrm{O}-\mathrm{H}$ and $\mathrm{C}=\mathrm{O}$ groups which might be contained in tannin compound have a specific absorption peak in the wavenumber range of $3500-3200 \mathrm{~cm}^{-1}$ and $1725-1705 \mathrm{~cm}^{-1}$, respectively. The aromatic compounds have absorption peaks in the range of 1404-1515 $\mathrm{cm}^{-1}$ and $1058 \mathrm{~cm}^{-1}$ for C-O. It can be concluded that the tannin from Uncaria gambir Roxb. plays an important role to reduce the metal ion and resulting in CuNPs formation. Figure-2a showed a peak at $622 \mathrm{~cm}^{-1}$ which indicates the presence of $\mathrm{Cu}$ ion. The formation of a new peak at 800 $\mathrm{cm}^{-1}$ is due to the peak shifting from 622 to $800 \mathrm{~cm}^{-1}$ which indicates the formation of CuNPs.

Figure-2b shows a diffraction pattern of synthesized CuNps. was the diffraction peak standard of facecentered cubic. Three main peaks in $2 \theta$ of $43.3^{\circ}, 50.4^{\circ}, 74.5^{\circ}$ were observed, referred to face-centered 


\section{RASĀYAN J. Chem.}

Vol. 12 | No. 4 |1752 - 1756| October - December | 2019

cubic structured metallic cupper based on ICSD \#627114 standard. This is due to the absence of $\mathrm{CuO}$ and $\mathrm{Cu}_{2} \mathrm{O}$. This result clearly suggested that the Uncaria gambir Roxb. leaf extract successfully reduced $\mathrm{Cu}^{2+}$ and $\mathrm{CuO}$ and mediated the formation of CuNps. A similar phenomenon was reported by Nasrollahzadeh ${ }^{21}$ on CuNPs synthesized using Plantago asiatica leaf extract. The average crystal size of CuNPs was calculated according to the Debye-Scherrer's formula and found to be $4.67 \mathrm{~nm}$.

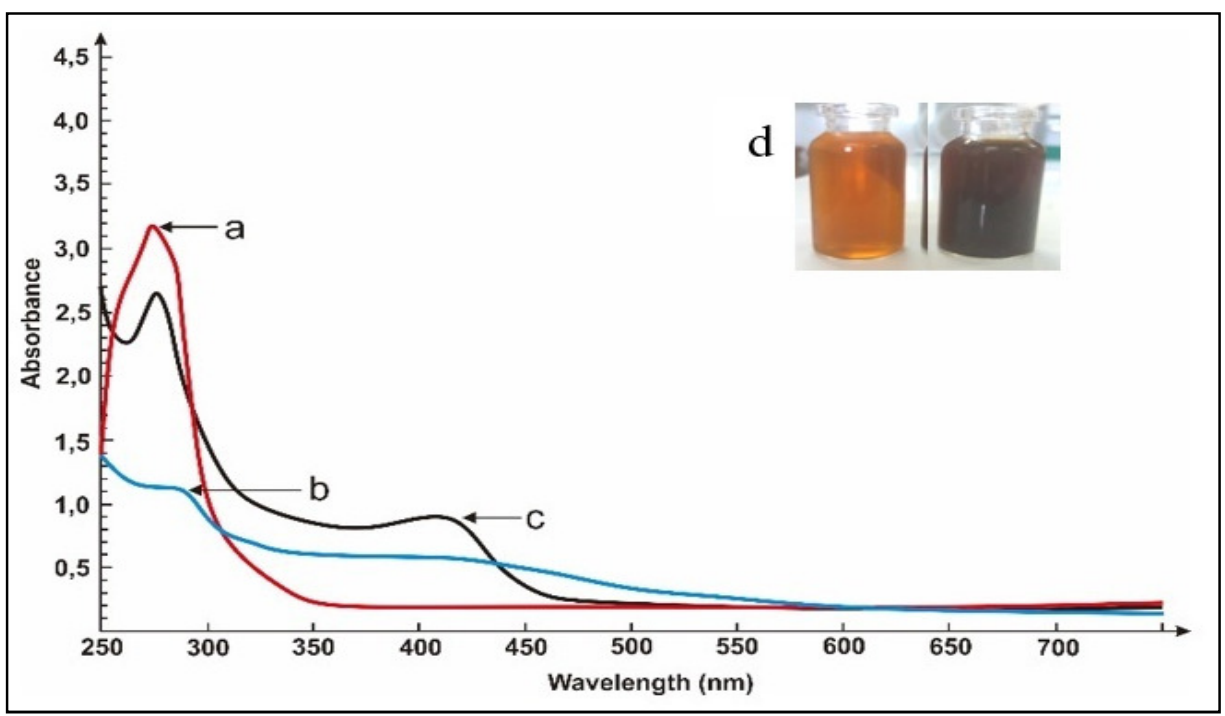

Fig.-1: UV-Vis Spectrophotometer Analysis of (a) Uncaria gambir Roxb. Leaf Extract, (b) CuSO4, (c) CuNps after 14 days. The inset Picture Shows Cu Nps Before and After 21 days
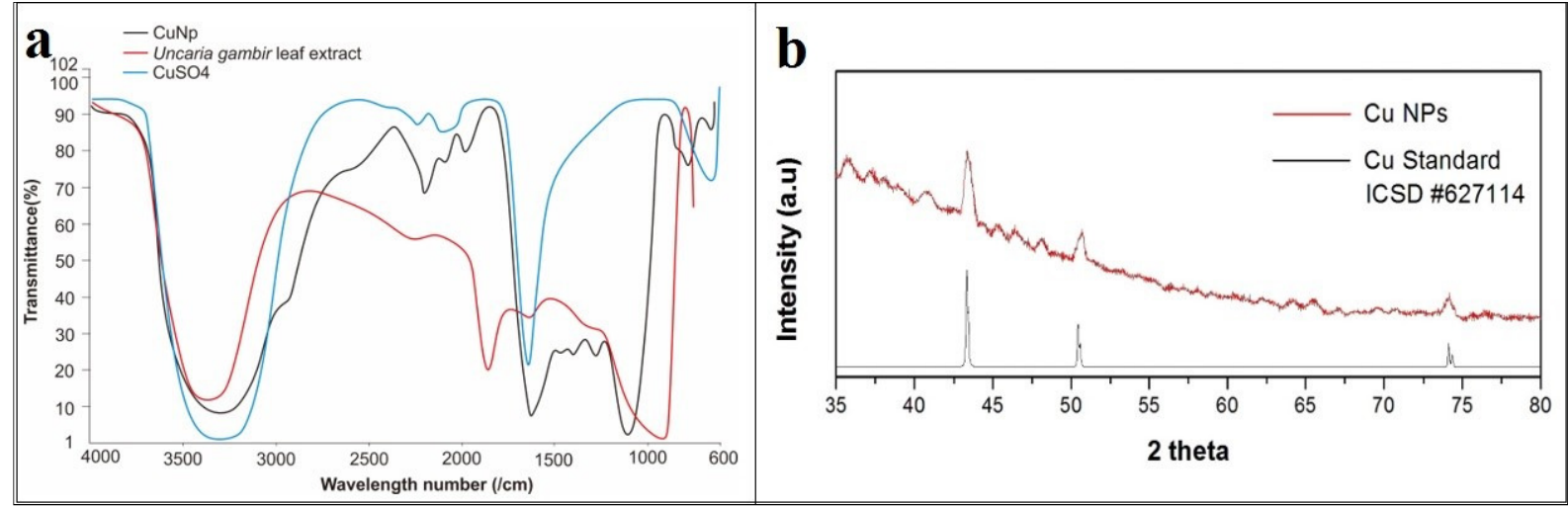

Fig.-2: (a.) FT-IR Analysis Spectrum (b.) XRD Pattern of Copper Nanoparticles
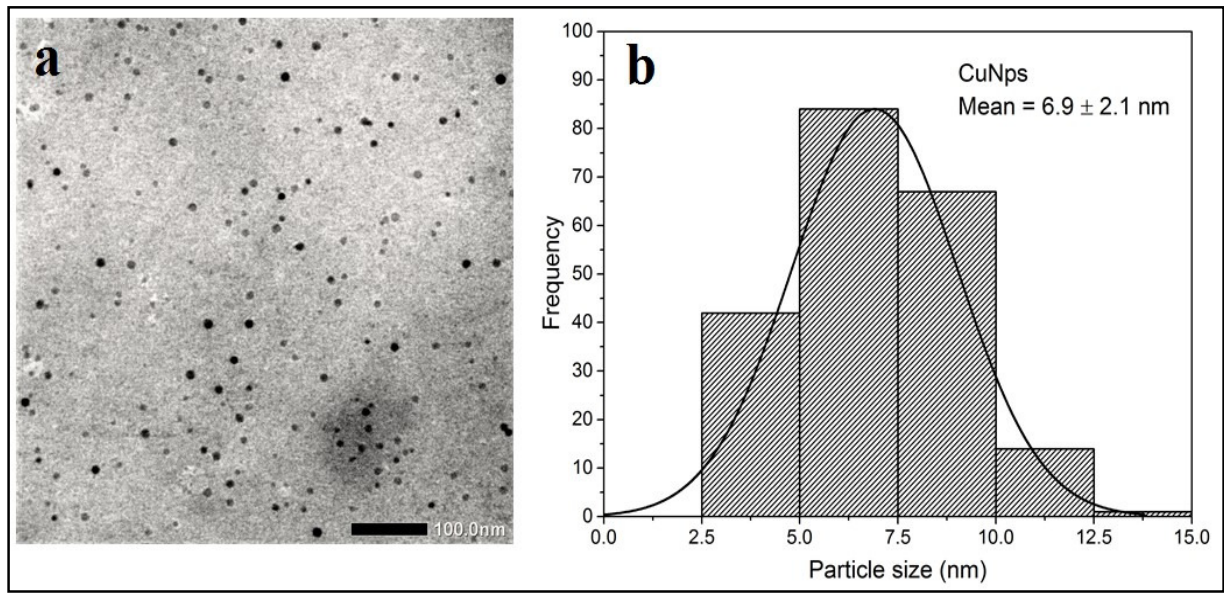

Fig.-3: (a.) TEM Image Copper Nanoparticle and (b.) Particle Size Distribution of Copper Nanoparticles 


\section{RASĀYAN J. Chem.}

Vol. 12 | No. 4 |1752 - 1756| October - December | 2019

The morphological of copper nanoparticle was displayed by TEM image in Fig.-3. The copper nanoparticle was in a spherical shape and agglomerated in every section with a diameter range of 2.5-15 $\mathrm{nm}$. The mean diameter was observed to be 6.9-2.1 nm (Fig.-3a). The particle size distribution was obtained using ImageJ (Fig.-3b), where the dominant distribution of the size was in 5-7.5 nm in diameter (about $40 \%$ of all particles). This result showed that synthesized copper nanoparticles were smaller in size than the previous report by Saranyaadevi. ${ }^{22}$ Compared to previous studies, our study has shown the production of copper nanoparticles with smaller size using Uncaria gambir Roxb. as bioreducing agent. This phenomenon might be due to the better performance of Uncaria gambir in reducing copper cation, which is related to the structure of the active compound in the plant extract.

Table-1: Comparison of Particle Size on Precursor Variations and Extracts

\begin{tabular}{c|c|c|c|c}
\hline Precursor & Extract & Crystal Structure & Particles Size (nm) & Refferences \\
\hline $\mathrm{CuSO}_{4}$ & O. Sanctum & FCC & 77 & Kulkarni et al $^{23}$ \\
\hline $\mathrm{CuCl}_{2}$ & P. asiatica & Spheric & $7-45$ & ${\text { Nasrollahzadeh et } \mathrm{al}^{21}}^{21}$ \\
\hline $\mathrm{Cu}\left(\mathrm{NO}_{3}\right)_{2}$ & C. papaya & FCC & 20 & Suresh et al \\
\hline $\mathrm{CuSO}_{4}$ & U. gambir Robx & FCC & 6,9 & This work \\
\hline
\end{tabular}

This possibility is caused by high levels of tannin in Uncaria gambir roxb which makes the reduction process run well, cap the nanoparticles and control the growth. As a result, it controls the size of the nanoparticles.

\section{CONCLUSION}

A synthesis route of nanoparticles in a simple way using natural materials was successfully conducted. The UV-Vis analysis confirmed the formation of copper nanoparticles with an absorption peak at $411 \mathrm{~nm}$. FTIR spectrum showed the formation of a new peak at $800 \mathrm{~cm}^{-1}$. The XRD analysis showed the formation of well crystallite face-centered cubic structured of copper nanoparticles. This research showed that Uncaria gambir Roxb. can be used to synthesize stable small-sized copper nanoparticles with good potential to be developed in some fields. This method provides many advantages such as non-toxic, easy to do, relatively low cost, short implementation time, and environment-friendly, because of the use of unharmful chemical materials.

\section{ACKNOWLEDGMENT}

One of the authors would like to thank the Education and Training Center of the Ministry of Industry for funding this research.

\section{REFERENCES}

1. J. Ramyadevi, K. Jeyasubramanian, A. Marikani, G. Rajakumar and A. A. Rahuman, Mater. Lett., 71, 114(2012), DOI: $10.1016 /$ j.matlet.2011.12.055

2. I. Ban, J. Stergar, M. Drofenik, G. Ferk and D. Makovec, J. Magn. Magn. Mater., 323(17), 2254(2011), DOI: $10.1016 /$ j.jmmm.2011.04.004

3. M. Raja, J. Shuba, F. B. Ali and S. H. Ryu, Mater. Manuf. Process., 23(8), 782(2008), DOI: $10.1080 / 10426910802382080$

4. A. Safonov, V. Sulyaeva, N. Timoshenko and S. Starinskiy, Phys. Lett. Sect. A Gen. At. Solid State Phys., 381(25-26), 2103(2017), DOI: 10.1016/j.physleta.2017.04.031

5. Z. Qiu-Li, Y. Zhi-Mao, D. Bing-Jun, L. Xin-Zhe and G. Ying-Juan, Trans. Nonferrous Met. Soc. China (English Ed., 20(s1), s240(2010), DOI: 10.1016/S1003-6326(10)60047-7

6. N. Karikalan, Rasayan J. Chem., 11(4), 1451(2018), DOI: 10.31788/RJC.2018.1143068

7. Y. Suresh, S. Annapurna, A. K. Singh and G. Bhikshamaiah, Int. J. Innov. Res. Sci. Eng. Technol., 3(4), 11265(2014).

8. H. J. Lee, J. Y. Song and B. S. Kim, J. Chem. Technol. Biotechnol., 88(11), 1971(2013), DOI: $10.1002 / j \mathrm{jctb} .4052$

9. C. T. Handoko, A. Huda, M. D. Bustan, B. Yudono and F. Gulo, Rasayan J. Chem., 10(4), 1137(2017), DOI: $10.1002 /$ jctb.4052

10. V. Vadlapudi, M. Behara and M. Nagalakshmi Devamma, Rasayan J. Chem., 7(3), 219(2014).

11. A. Rauf, Rahmawaty and A. Z. Siregar, Procedia Chem., 14, 3(2015), DOI: 10.1016/j.proche.2015.03.002 


\section{RASĀYAN J. Chem.}

Vol. 12 | No. 4 |1752 - 1756| October - December | 2019

12. S. Arief, V. Gustia, D. V. Wellia, Zulhadjri, T. Ban and Y. Ohya, J. Chem. Pharm. Res., 7(9S), 189(2015).

13. S. Arief, P. Hidayani, L. Aferta, Zulhadjri, T. Ban and Y. Ohya, Orient. J. Chem., 33(1), 87(2017), DOI: $10.13005 / \mathrm{ojc} / 330109$

14. A. Labanni, Z. Zulhadjri, D. Handayani and Y. Ohya, J. Dispers. Sci. Technol., 1(2019), DOI: $10.1088 / 1757-899 X / 299 / 1 / 012067$

15. A. Labanni, Zulhadjri, D. Handayani and S. Arief, IOP Conf. Ser. Mater. Sci. Eng., 299(1), 1(2018), DOI: $10.1080 / 01932691.2019 .1626249$

16. A. N. Pestryakov, V. P. Petranovskii, A. Kryazhov, O. Ozhereliev, N. Pfänder and A. Knop-Gericke, Chem. Phys. Lett., 385(3-4), 173(2004), DOI: 10.1016/j.cplett.2003.12.077

17. T. M. D. Dang, T. T. T. Le, E. Fribourg-Blanc and M. C. Dang, Adv. Nat. Sci. Nanosci.Nanotechnol., 2(1), 1(2011), DOI: 10.1088/2043-6262/2/1/015009

18. M. Salavati-Niasari, F. Davar and N. Mir, Polyhedron, 27(17), 3514(2008), DOI: 10.1016/j.poly.2008.08.020

19. S. Fatma, K. P, E. Ravindran and R. S, Asian J. Pharm. Clin. Res., 10(4), 79(2017), DOI: 10.22159/ajpcr.2017.v10i4.15744

20. A. D. Brumbaugh, K. A. Cohen and S. K. S. Angelo, ACS Sustain. Chem. Eng., 2(8), 1933(2014), DOI: $10.1021 / \mathrm{sc} 500393 \mathrm{t}$

21. M. Nasrollahzadeh, S. S. Momeni and S. M. Sajadi, J. Colloid Interface Sci., 506, 471(2017), DOI: 10.1016/j.jcis.2017.07.072

22. K. Saranyaadevi, V. Subha, R. S. E. Ravindran and S. Renganathan, Int. J. ChemTech Res., 6(10), 4533(2014).

23. V. D. Kulkarni and P. S. Kulkarni, Int. J. Chem. Stud., 1(3), 1(2013).

[RJC-5347/2019] 